\title{
Review
}

Dev Neurosci 2018;40:437-450

DOI: $10.1159 / 000496467$
Received: October 1, 2018

Accepted after revision: December 20, 2018

Published online: April 17, 2019

\section{The Arginase Pathway in Neonatal Brain Hypoxia-Ischemia}

\author{
Jana Krystofova Praneeti Pathipati Jeffrey Russ Ann Sheldon \\ Donna Ferriero \\ Department of Pediatrics, University of California San Francisco, San Francisco, CA, USA
}

\section{Keywords}

Arginase $\cdot$ Hypoxia-ischemia $\cdot$ Neuroinflammation .

Neonatal brain

\begin{abstract}
Brain damage after hypoxia-ischemia (HI) occurs in an agedependent manner. Neuroprotective strategies assumed to be effective in adults might have deleterious effects in the immature brain. In order to create effective therapies, the complex pathophysiology of $\mathrm{HI}$ in the developing brain requires exploring new mechanisms. Critical determinants of neuronal survival after $\mathrm{HI}$ are the extent of vascular dysfunction, inflammation, and oxidative stress, followed later by tissue repair. The key enzyme of these processes in the human body is arginase (ARG) that acts via the bioavailability of nitric oxide, and the synthesis of polyamines and proline. ARG is expressed throughout the brain in different cells. However, little is known about the effect of ARG in pathophysiological states of the brain, especially hypoxia-ischemia. Here, we summarize the role of ARG during neurodevelopment as well as in various brain pathologies.

(c) 2019 S. Karger AG, Basel
\end{abstract}

\section{Introduction}

Hypoxic-ischemic brain injury accounts for a significant proportion of mortality and long-term disability in children, affecting 0.7-1.2 million infants annually [1]. While progress in respiratory and intensive care technology has greatly improved survival rates, the incidence of motor and cognitive disorders linked to perinatal and early postnatal brain injury has actually increased in the last 2 decades [2]. Despite the significant socioeconomic burden of neonatal hypoxia-ischemia (HI), there are currently very few preventative and/or protective therapies available for patients who have suffered brain injury from HI, with only one treatment licensed for use, i.e., hypothermia. The etiology of HI is complex, with a clear initial primary-insult phase followed by a more delayed, secondary-injury phase that can continue for long periods of time. While the initial, primary insult contributes to neuronal cell death, the degree of secondary injury induced by inflammation and oxidative stress is perhaps the more critical determinant of neuronal survival. Many factors contribute to cell death in this extended injury phase [3] and, given its duration, this phase can easily be considered the most viable time period to initiate effective therapy.

\section{KARGER}

(c) 2019 S. Karger AG, Basel

E-Mail karger@karger.com

www.karger.com/dne
Jana Krystofova

Department of Pediatrics, UCSF Weill Institute for Neurosciences University of California San Francisco

675 Nelson Rising Lane 415, Box 0663, San Francisco, 94143 CA (USA)

E-Mail jana.krystofova@ucsf.edu 
Fig. 1. Schematic diagram of relationship between ARG and NOS isoforms in the brain. NOS, nitric oxide synthase; ARG, arginase; eNOS, endothelial NOS; iNOS, inducible NOS; nNOS, neuronal NOS; NO, nitric oxide; GABA, $\gamma$-aminobutyric acid.

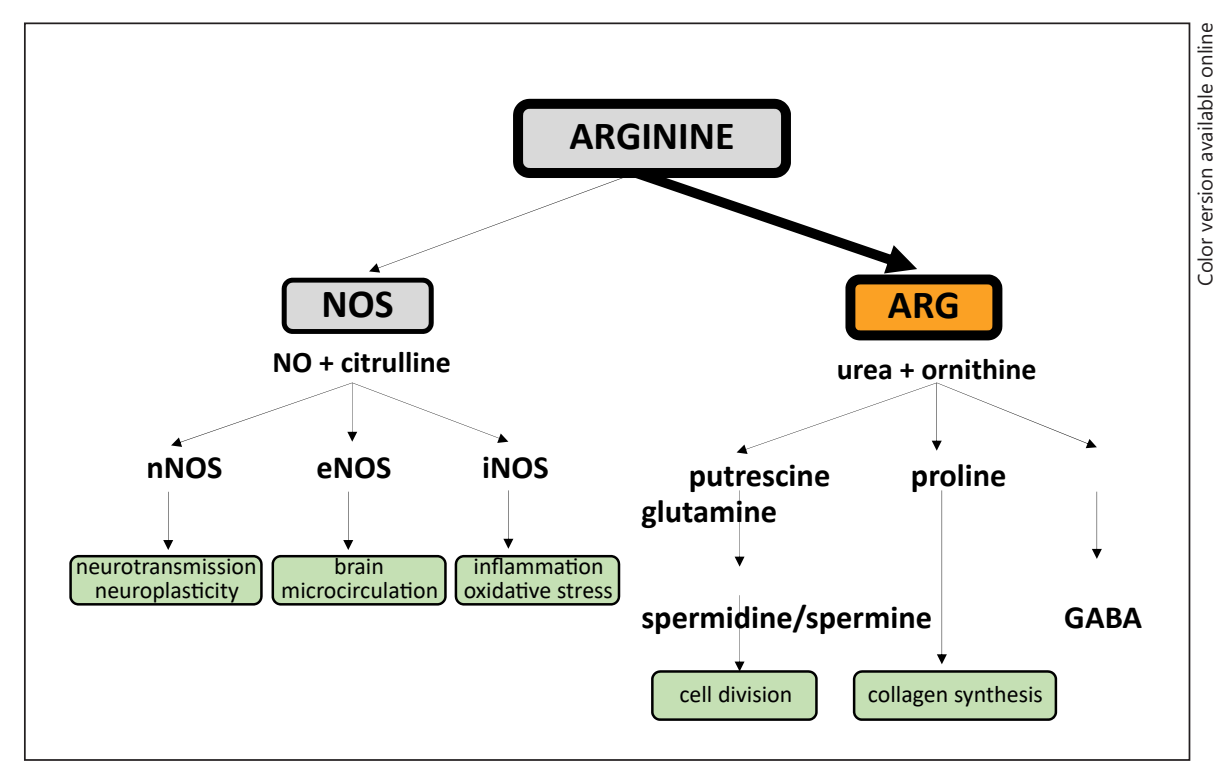

Arginases (ARG) are enzymes expressed throughout the brain in 2 known isoforms and have conventionally been studied in their role as the penultimate step in the urea cycle [4]. However, more recent evidence reveals the breadth of different roles that ARG play, particularly in various disease states, in both beneficial and detrimental ways [5]. Given that ARG are among the most acutely upregulated enzymes in models of ischemic injury (of the heart [6], liver [7], and retina [8]) and key regulatory enzymes of many inflammatory states, elucidating the molecular mechanisms of the ARG pathway will enable the development of more effective therapies to improve outcomes. We speculate that it is ultimately the complex interplay between the individual characteristics of the ARG isoenzymes, their interactions with other coregulators, and their temporal expression patterns that determine the specific effects of ARG, particularly in the central nervous system (CNS) after hypoxicischemic injury.

\section{Arginase}

\section{ARG Isoforms and Expression}

ARG is expressed as 2 isoforms, arginase 1 and 2 (ARG-1 and ARG-2), that differ in their genetic coding, subcellular localization, tissue distribution, immunological cross-reactivity, molecular regulation, and function $[9,10]$. ARG-1 is a cytosolic, homotrimer enzyme with a $35-\mathrm{kDa}$ subunit [9] encoded by the arg1 gene located on chromosome 6q23 [11]. It is constitutively and abundantly expressed in the liver, and some ARG-1 expression has also been reported in several extrahepatic tissues such as the brain, stomach, pancreas, and lung $[10,12]$. The second isoform, ARG-2, is a $40-\mathrm{kDa}$, mitochondrial enzyme encoded by the arg2 gene located on chromosome 14q24.1-24.3 [13]. Unlike ARG-1, ARG-2 is confined mainly to the kidney, brain, prostate, intestine, and pancreas [10,12-14]. Both isoforms of ARG share a similar structure, with $>50 \%$ homology of their amino acid residues, and $100 \%$ homology in the areas critical for their L-arginine metabolizing function [13-15]. This suggests an overlap in their metabolizing functions, but their individual functional impact is highly specific to cell and organ types.

\section{ARG Functions}

ARG is a metalloenzyme involved in the urea cycle, a series of biochemical reactions that produce urea from ammonia for excretion. Specifically, it is involved in the penultimate step, the hydrolysis of the semiessential amino acid L-arginine to form L-ornithine and urea [4]. The breakdown of L-arginine plays an important regulatory role in the formation of active biomolecules including nitric oxide (NO), citrulline, polyamines, and proline among others (Fig. 1).

The primary function of ARG-1 is detoxification by removing excessive nitrogen produced from amino acid metabolism through the hepatic urea cycle [4]. ARG-1 knockout mice exhibit severe symptoms of hyperammo- 
nemia and do not survive past postnatal day 10 (P10)P14 [16], while patients with genetic mutation-induced ARG-1 deficiency demonstrate hyperammonemia and symptoms that mostly involve the CNS, like progressive spastic paraparesis, epileptic seizures, and psychomotor and growth retardation [17]. On the other hand, ARG-1 overexpression and an increase in ARG activity have been associated with various complex disease states, implicating ARG as a key regulatory enzyme in inflammation [18] and repair [19]. Examples are: pulmonary disease [20], diabetes [21], carcinogenesis [22], hypoxic-ischemic and reperfusion injury in different organs [23-28], and cardiovascular disease $[23,29]$.

While the overall role of ARG-2 has remained unknown for some time, more recent studies have begun to uncover its role in vascular endothelial damage via oxidative stress [30-32] and mitochondrial dysfunction [33]. Identified as the predominant isozyme in human and mouse endothelial cells $[34,35]$, ARG-2 is implicated in the regulation of endothelial senescence $[30,35]$ and function in many disease states [34, 36, 37]. Specifically, ARG-2 hydrolyzes L-arginine in vascular endothelial cells, thereby limiting its availability for the generation of NO via endothelial NO synthase (eNOS), and resulting in vascular endothelial dysfunction [38], oxidative stress, and the enhanced expression of endothelial inflammatory adhesion molecules [30]. Loss of both genes for ARG-2 in ARG-2 knockout mice leads to a systemic hypertension phenotype with a blunted response to vasoconstriction [39]; this highlights a prominent role for ARG-2 in endothelial dysfunction.

The discovery of ARG-1 and ARG-2 expression in the brain has raised the question of whether a complete urea cycle occurs in brain and what its role might be. Previously, it was claimed that the complete urea cycle may not occur in the brain; however, many of the recent reports to have emerged from the study of Alzheimer's and Huntington disease established the presence of elevated urea levels and urea cycle genes in the brain [40, 41]. These findings have garnered much interest in the role of ARG in the brain, and studies have started focusing on the regulation of ARG and other elements in specific disease states and how modulating members of the urea cycle may affect these disease states. Data on the role of ARG after brain HI are limited, and some are conflicting. However, all recent studies point out that ARG responds to $\mathrm{HI}$ conditions in the brain and may play a pivotal role in neural injury, especially via the NO pathway and repair via the ARG effect on polyamine synthesis.

Arginase in Brain Injury
ARG and the NO Pathway

NO is a well-known signaling molecule of great interest, particularly in the CNS. It is produced by NOS, an enzyme with many cellular isoforms that regulate the expression and function of NO based on cellular location. Neuronal (n)NOS (NOS-1) and eNOS (NOS-3) are commonly associated with the nanomolar levels of NO production that mediate intracellular signaling processes and vascular homeostasis, respectively [42]. Inducible (i)NOS (NOS-2) produces high levels of NO in the micromolar range and plays an important role in tissue inflammation and host defenses [43]. The substrate for NOS activity and $\mathrm{NO}$ formation is L-arginine, and, consequently, NOS function is reciprocally regulated by ARG via substrate depletion [42]. Interestingly, although the affinity of Larginine is for purified NOS ( $\mathrm{Km}$ approx. $2-20 \mu \mathrm{M}$ ) is much higher than for ARG (Km approx. 1-5 mM), as the maximum activity of ARG is $>1,000$ times that of NOS, similar rates of substrate utilization occur at physiologic L-arginine concentrations [15].

Several findings suggest that the limitation of NO production by ARG, and therefore its physiologic function, is critically dependent on the particular combination of ARG isoform with NOS isoform. Upregulation of either ARG-1 or ARG-2 is effective in limiting NO production by iNOS; however, considering that the rate of L-arginine utilized by nNOS is much lower than that used by iNOS, a similar outcome cannot be assumed for nNOS [42]. The decrease in nitrite production by nNOS correlates with an increase of cytosolic ARG-1 activity but not mitochondrial ARG-2 activity [42]. For eNOS, however, the overexpression of ARG-2 is able to inhibit NO production, although the effect is smaller than that of transgene ARG1 [44], thus highlighting the specificity of enzyme function based on isoform and location. Interestingly, the intermediate in $\mathrm{NO}$ synthesis, $\mathrm{N} \omega$-hydroxy-L-arginine, and the ARG product L-ornithine, decrease ARG activity, suggesting there are multiple factors in the regulation of ARG-NOS interactions and metabolic pathways [20].

\section{ARG and Polyamine and Proline Pathways}

The effect of ARG on polyamine or proline synthesis is dependent on the subcellular colocalization of the ARG isoforms with the enzymes of polyamine or proline pathways. The colocalization of ARG-1 with ornithine decarboxylase in the cytosol directs ornithine, a product of ARG metabolism, towards polyamine synthesis [44]. In contrast, when ARG-2 is colocalized in mitochondria with ornithine aminotransferase, ornithine preferentially forms proline and glutamate [44]. Considering that orni-

Dev Neurosci 2018;40:437-450 
thine is a precursor for the neurotransmitter synthesis of both glutamate and $\gamma$-aminobutyric acid (GABA) [45], the cellular localization and activities of these 2 isoforms could play a major role in mediating neurotransmitter levels and the subsequent responses to injury processes. However, in ARG-1 $1^{-/}$mice, while there was a mild decrease in net brain glutamine compared to littermate controls, GABA levels remained unchanged [46], suggesting additional regulatory mechanisms and not ARG-1 alone. Polyamines (namely putrescine, spermidine, and spermine) are intracellular, and interact with nucleotides and phospholipids and, consequently, are involved in many functions related to cell survival, proliferation, maturation, and neurite growth among others [47, 48]. Polyamines can also exert harmful effects, such as neuronal damage from excitotoxicity via the overactivation of $\mathrm{N}$ methyl-D-aspartate (NMDA) receptor [49]. Therefore, depending on the context, ARG may play a beneficial or detrimental role via the modulation of excitotoxicity or tissue repair.

\section{The ARG Pathway in the Brain}

\section{ARG Localization in the Brain}

Within the CNS, the 2 isoforms of ARG differ in their regional, cellular, and subcellular expression patterns. ARG-1 and ARG-2 are both expressed throughout the brain of chickens [50] and rodents [12], with ARG-1 expressed at higher levels than ARG-2 [12]. In rats, expression of ARG-1 and ARG-2 has been detected in the cortex, hippocampus, thalamus, basal ganglia, cerebellum, brainstem, and spinal cord among other substructures $[10,12,51-53]$. Within these regions, ARG has been noted to be localized to variable cellular subtypes. In the hippocampus, ARG expression is found in both excitatory and inhibitory neurons [51]; in the cerebellum, expression has been noted in basket, stellate, Golgi, and Purkinje cells $[51,52]$. Although some initial studies suggested that ARG expression is confined to the neurons [12], further study clarified that both isoforms are expressed in the glia, i.e., oligodendrocytes and microglia $[10,51,53]$, and in astrocytes [54]. It remains to be elucidated which cells represent the major sources of ARG in HI conditions of the brain, and what changes occur in terms of ARG activity and expression as the injury evolves.

\section{ARG Spatiotemporal Changes in the Brain with Age}

Damage in the neonatal brain after $\mathrm{HI}$ is both regionand cell-specific [3] and involves development-specific processes that are markedly different from in the adult brain [55]. Therefore, understanding ARG spatiotemporal changes during development is critical.

ARG expression and activity both undergo spatiotemporal changes with age. ARG-1 expression in the murine brain and in the ganglion cells of the peripheral nervous system have been noticed as early as embryonic life; positive staining is seen from embryonic day (E) 13 to P1, and peaks at E15-E17 [56]. Expression is evident in the cervical, thoracic, and lumbar dorsal-root ganglia (DRG), confined to sensory neuron cell bodies from E13 to P1, in the vagal nucleus, and in the medulla at E17 [56]. Relatively high expression of ARG-1 was found in microglial cells early in the postnatal period (P3), and this had diminished by $70 \%$ at $\mathrm{P} 21$ and by $>90 \%$ at 12 months [57]. This pattern parallels that of microglial iNOS, suggesting a temporal link between the 2 enzymes that utilize L-arginine, though the details of these interactions in microglial development are yet to be elucidated [57]. ARG-2 expression, on the other hand, is undetectable at earlier stages (E13-P1) [56] but is evident in adulthood [12, 53]. Similarly, ARG expression peaks in the brain and retina shortly after the chicks hatch, and then slowly declines by adulthood [50].

ARG activity appears to change in association with changes in brain molecular structure and function. In rats, gross ARG brain activity is highest in fetal and neonatal brains, and then decreases 4 -fold by adulthood [58]. In young adult rats, ARG activity is highest in the postrhinal cortex and in subregions of the hippocampus, particularly the dentate gyrus, followed by CA2 $2 / 3$, and then CA 1. Lower ARG activity has been found in the temporal cortex, and the lowest is in the entorhinal and perirhinal cortices $[59,60]$. There are no significant differences in ARG activity or expression in the prefrontal cortex in young and aged rats [61]; however, ARG activity in the postrhinal cortex decreases with age $[59,60]$. These findings conflict somewhat with another study by the same group that found a significant increase in ARG activity only in the perirhinal cortex of aged rats [62], and a similar finding was described in an animal model that compared 1-month-old and 14-month-old mice [63].

ARG activity does not, however, appear to correlate with expression levels, as the highest expression of ARG1 has been noted in postrhinal and perirhinal cortices and significantly lower expression in the entorhinal cortex, dorsal hippocampus, and temporal cortex [60]. ARG-2 expression, in contrast, does not vary by region. As the mice aged, no change was noted in the expression of either isoform, ARG-1 or ARG-2, across hippocampal re- 
gions. There was a clear temporal pattern for hippocampal ARG activity, however, which decreased with age in CA1 and CA2/3, but not in the dentate gyrus.

These studies draw attention to the fact that spatiotemporal and age-dependent variations in ARG expression and activity clearly exist in the brain and are perhaps indicative of the differential regulation of each of these regions during development and, conceivably, after injury.

\section{The Role of ARG in Neurodevelopment}

While several studies have now established the importance of ARG and its downstream products in embryogenesis and placental development, few have specifically investigated the role of ARG in early neurodevelopment.

ARG activity is noted to be highest during the periods of highest protein and polyamine synthesis [58, 64, 65], suggesting a pivotal role for this enzyme that starts early in development. ARG knockout animals exhibit decreased dendritic complexity, intrinsic excitability, synapse numbers, and functional synaptic deficits, consistent with the anatomical changes observed with an unexpected gradation of abnormalities based on whether it is a single- or double-copy loss of arg1. Gene therapy with arg1 at neonatal stages rescues nearly all of these abnormalities [66].

Intriguingly, however, neural stem cells isolated from the germinal zones of ARG-1 knockout embryos were found to be capable of differentiating into neurons, oligodendrocytes, and astrocytes [67]. They appeared to mature more rapidly than wild-type and heterozygous stem cells, elaborating for longer, with more complex neurites, and more frequently expressing mature neuronal markers such as $\beta 3$-tubulin and neurofilament. It is possible that a compensatory upregulation of agmatinase and spermine synthase in ARG-1 knockout neural stem cells may upregulate alternative polyamine synthesis pathways and intermediate substrates, circumventing the loss of ARG-1 to continue polyamine-dependent proliferation [67]. Together, it appears that while alternative pathways of polyamine synthesis may enable the anatomical differentiation and maturation of neurons in states of ARG deficiency, ARG is still necessary for the formation of the dendritic network and synaptic connections.

In early neurons, the strict temporal control of neuronal ARG expression appears to have developmental consequences for axon growth. In cultured DRG neurons [47], ARG levels were initially high in the young neurons; this correlated with the myelin-induced promotion of axon growth early in development. However, with a pre- dictably timed drop in ARG activity at P4, the effect of myelin rapidly switched to inhibit axon growth. It was suggested that neurotrophin signaling elevated cAMP levels, activating the transcription of ARG-1 which then indirectly increased levels of polyamines, leading to axon growth by overcoming the inhibitory signals of myelin. When cAMP spontaneously dropped at age P4, this molecular pathway was downregulated, and inhibitory signaling from myelin prevented further axon elaboration.

ARG-1 is thus thought to play a fundamental role in the promotion of axon growth, by improving the ability of axons to overcome the actions of inhibitory factors such as myelin-associated glycoprotein (MAG) in late postnatal neuronal development and also after CNS injury. Overexpression of ARG-1 and the addition of polyamines both enhanced axon growth in cultured cerebellar neurons grown on myelin, while inhibitors of ARG and ornithine decarboxylase blocked axon growth, presumably by preventing the conversion of arginine to ornithine or ornithine to polyamines, respectively [47].

ARG clearly plays a critical role in neurodevelopment, neurogenesis, and axonal repair mechanisms. As such, understanding the developmental patterns and modulation of this pathway following injury, especially after HI, is a critical first step towards developing effective therapeutic strategies.

\section{ARG Response after Brain Injury}

\section{Changes in ARG Expression and Activity}

To date, 3 phases of injury progression have been described after neonatal brain HI: the acute primary energy failure due to the hypoxic-ischemic insult; a secondary, subacute phase which is a consequence of reoxygenation and reperfusion; and a tertiary, chronic phase in which previous events can get worse and inflammation becomes chronic [68]. ARG appears to respond to all phases by changes in its activity and expression.

In a rat model of anoxia-hypoxia, ARG expression remained unchanged during periods of anoxia but increased significantly during the reperfusion phase 5 days after the insult [69]. Similarly, Quirié et al. [70], using a rat photothrombotic model of brain ischemia, observed that while the ARG-2 isoform was not modified by the injury, ARG-1 expression increased at the injury site on day 8 , peaking on day 15 . They also noted a $29 \%$ decrease in ARG-1 activity compared to controls, postulated to be due to a possible delayed expression of endogenous ARG inhibitors. Another report, by Hamzei Taj et al. [71], 
Table 1. Summary of the studies describing the ARG pathway after stroke, hypoxia, and traumatic brain injury

\begin{tabular}{|c|c|c|c|c|}
\hline $\begin{array}{l}\text { First author } \\
\text { [ref.], year }\end{array}$ & Animal model & $\begin{array}{l}\text { Timeline for measurement of } \\
\text { changes in ARG pathway after injury }\end{array}$ & Adult/pup & Observed effect(s) \\
\hline $\begin{array}{l}\text { Ahmad [24], } \\
2016\end{array}$ & $\begin{array}{l}\text { Male C57BL/6 wild-type and Arg- } 2 \\
\text { knockout mice; MCAO }\end{array}$ & day 7 & adult & Higher infarction volumes and neurologic deficits; excitotoxic damage \\
\hline $\begin{array}{l}\text { Hamzei Taj } \\
{[71], 2016}\end{array}$ & $\begin{array}{l}\text { Male C57BL/6 wild-type mice; } \\
\text { MCAO }\end{array}$ & days 6 and 14 & adult & $\begin{array}{l}\text { ARG-1 expression highest 1st week; number of Arg-1+ microglia/ } \\
\text { macrophages correlated with neuronal protection and functional } \\
\text { improvement after miRNA-124 treatment }\end{array}$ \\
\hline $\begin{array}{l}\text { Barakat } \\
{[141], 2018}\end{array}$ & $\begin{array}{l}\text { Male Wistar wild-type rats; } \\
\text { MCAO }\end{array}$ & not stated & adult & $\begin{array}{l}\text { Increased ARG-1 and ARG-2 expression inhibited by L-citrulline and } \\
\text { L-ornithine treatment; } \\
\text { reduction of infarct size and brain edema }\end{array}$ \\
\hline $\begin{array}{l}\text { Clarkson } \\
{[25], 2004}\end{array}$ & $\begin{array}{l}\text { Male Wistar wild-type rat pups; } \\
\text { MCAO }\end{array}$ & day 7 & pup & $\begin{array}{l}\text { Significant decrease in infarction size and ARG activity after spermine } \\
\text { supplementation }\end{array}$ \\
\hline $\begin{array}{l}\text { Clarkson } \\
{[26], 2005}\end{array}$ & $\begin{array}{l}\text { Male Wistar wild-type rat pups; } \\
\text { MCAO followed by hypoxia }\end{array}$ & days 3 and 90 & pup & $\begin{array}{l}\text { Increased ARG activity after } \mathrm{HI} \text { on day 3, persistent increase on day } 90 \\
\text { after HI; decreased ARG activity after clomethiazole; neuroprotection }\end{array}$ \\
\hline $\begin{array}{l}\text { Gao [135], } \\
2017\end{array}$ & $\begin{array}{l}\text { Male C57BL/6 wild-type mice; } \\
\text { TBI: CCI }\end{array}$ & day 3 & adult & $\begin{array}{l}\text { Treatment with IL-2C significantly increased the number of ARG-1+ } \\
\text { cells around the lesion area }\end{array}$ \\
\hline $\begin{array}{l}\mathrm{Xu}[136] \\
2017\end{array}$ & $\begin{array}{l}\text { C57BL/6 wild-type mice; } \\
\text { TBI model: CCI }\end{array}$ & days 1 and 3 & adult & $\begin{array}{l}\text { Increased ARG-1 expression in M2 microglia after atorvastatin } \\
\text { therapy }\end{array}$ \\
\hline $\begin{array}{l}\text { Bitner } \\
{[142], 2010}\end{array}$ & $\begin{array}{l}\text { C57Bl6/J and ARG-2 knockout mice; } \\
\text { TBI: CCI }\end{array}$ & $15 \mathrm{~min}$ and $1 \mathrm{~h}$ & adult & $\begin{array}{l}\text { The absence of ARG-2 significantly improved CBF recovery after } \\
\text { trauma }\end{array}$ \\
\hline $\begin{array}{l}\text { Swamy } \\
{[69], 2010}\end{array}$ & $\begin{array}{l}\text { Male Sprague-Dawley wild-type rats } \\
\text { exposed to anoxia for } 4-5 \mathrm{~min}\end{array}$ & day 5 & adult & Increased ARG expression; activity increased in reperfusion phase \\
\hline $\begin{array}{l}\text { Quirié } \\
{[70], 2013}\end{array}$ & $\begin{array}{l}\text { Wistar wild-type rats; } \\
\text { photothrombotic stroke model }\end{array}$ & days $1,8,15$, and 30 & adult & $\begin{array}{l}\text { Increased ARG-1 expression on day } 8 \text {; } \\
\text { ARG-2 unchanged; activity highest on day } 8\end{array}$ \\
\hline
\end{tabular}

HI, hypoxia-ischemia; MCAO, middle cerebral-artery occlusion; TBI, traumatic brain injury; CCI, controlled cortical impact; CBF, cerebral blood flow.

showed ARG-1 expression to be strongest within the first week after middle cerebral-artery occlusion (MCAO), and decreasing by the second week. Another study observed that a higher ARG-1 activity persists on day 90 after injury, suggesting that ARG-1 remains elevated for a longer period of time [26].

In terms of spatiotemporal expression after ischemic insult, increased ARG-1 expression localizes to activated microglia within the lesion core, whereas the neuronal ARG-1 expression is strongest in cortical neurons located in the nonaffected hemisphere. Lower ARG-1 expression is also found in astrocytes sporadically located within the glial scar [71]. In a photothrombotic model of ischemia, ARG-1 was found to be higher in activated macrophages, neurons, and astrocytes in the area of the lesion [70]. Interestingly, ARG-1 expression in astrocytes follows a similar pattern to that of brain derived-neurotrophic factor (BDNF), indicating a possible role of ARG in BDNF regulation, neuronal survival, growth, and neuroplasticity $[70,72]$.

It appears that the observed differences in ARG localization, expression, and activity in response to brain $\mathrm{HI}$ are age- and animal model-dependent, making it vital to extrapolate findings in a similarly appropriate manner to ensure accurate assessment (Table 1). Understanding the dynamics of ARG in response to brain hypoxic-ischemic insult and the role played by ARG in the pathophysiology of the injury at particular time points has important implications for appropriate therapeutic targeting of ARG pathway. In the immediate phase of injury, it may be the influence of ARG on the NO pathway that plays a significant role. While the effects of ARG inhibition might be detrimental, by increasing the availability of L-arginine for iNOS and nNOS as previously stated, it is possible that it is also beneficial by improving cerebral perfusion and attenuating vascular oxidative stress via the eNOS pathway. We postulate that inhibiting ARG in the acute phase of brain HI may decrease neurotoxicity by decreasing polyamine synthesis. However, ARG inhibition might not be favorable during the later stages of injury since polyamines and proline participate in tissue repair.

\section{ARG Regulation in the HI Environment}

HI creates a molecular environment of vascular dysregulation, oxidative stress, inflammation, and excitotoxicity that lead to progressive damage over a long period of time [3]. This damage is a critical determinant of permanent neuronal loss and poor clinical neuro- 
logical outcomes. Various mechanisms activated in response to neonatal brain HI alter the ARG metabolic pathway.

\section{Hypoxia}

The hypoxic environment induces both ARG expression and activity [73]. ARG-2 is stimulated by HIF-2 $\alpha$ [74], and HIF-2 $\alpha$ is one of the predominant adaptive responders to acute brain hypoxia in the oxygen-deprived environment after stroke [75]. Hypoxic upregulation of ARG-2 expression has been shown to also occur via AMPKal signaling [76], miRNAs [77], the PI3K-Akt pathway [78], the direct induction of the ARG-2 promoter over ARG-1 [79], and the activation of the extracellular signal-regulated kinase or epidermal growth factor receptor tyrosine kinase, which stimulate both ARG-1 mRNA and ARG2 mRNA expression [80-82]. Interestingly however, ARG-2 mRNA is suppressed by $>50 \%$ by $\mathrm{O}_{2}$ deprivation [83], suggesting that the exact influence of hypoxia on ARG in the brain remains to be clarified further.

\section{Ischemia and Reperfusion Injury}

ARG is upregulated during ischemia-reperfusion, and whether this is protective or detrimental is organ-dependent. In models of myocardial infarction, ARG-1 is one of the most abundant and fastest-upregulated genes [6, 84] with increased activity [85-87] following ischemiareperfusion injury. This upregulation has been shown to be largely detrimental, mostly likely by decreasing NO levels [87] and bioavailability [88]. The transcription factors Forkhead box O4 (FoxO4) [89] and tumor necrosis factor $\alpha$ (TNF- $\alpha)$ [90] have both been implicated in mediating this upregulation. In retinal ischemia-reperfusion injury models, ARG-2 deletion leads to significantly reduced glial activation, reactive oxygen species formation, and cell death by necroptosis, leading to decreased ganglion cell loss, microvascular degeneration, and preserved retinal morphology [8]. Similarly, in the small intestine [91] and liver [92], ARG blockade has been shown to increase L-arginine bioavailability, resulting in less injury in the liver following ischemia-reperfusion. Essentially, in reperfusion models of organs other than the brain, ARG upregulation following injury appears to have detrimental effects. While data from the brain are limited, a recent study has shown that deletion of ARG-2 in cerebral ischemia has detrimental effects, with higher infarction volumes, excitotoxic damage, decreased cerebral blood flow, and higher neurologic deficit scores [24], which clearly highlight organ-specific roles for this enzyme and its isoforms.

Arginase in Brain Injury

\section{ARG and the Molecular Mechanisms of Brain HI}

The source of ARG in tissue after hypoxic-ischemic injury varies. ARG may be released from damaged tissue cells, newly expressed in cells at the injury site, or originate from cells that migrate into the lesion like macrophages or microglia. In a model of spinal cord injury and autoimmune encephalitis, ARG-1 was expressed exclusively in infiltrating myeloid cells and not in microglia [93]. Zarruk et al. [94] observed a similar pattern, where macrophages upregulated the expression of ARG-1 mRNA and $A R G$ protein as a response to brain ischemia more than microglia did. The definitive sources of ARG after $\mathrm{HI}$ remain to be established. Different types of brain injury must be taken into consideration. For example, brain cells exposed to hypoxic injury may have an expression profiles that is different from in cells exposed to both hypoxia and ischemia.

\section{$A R G$ and Neuroinflammation}

Neuroinflammation is a critical aspect of injury and postinjury mechanisms in the brain, and it is conceivable that the regulators of neuroinflammation may play an important role in mediating both injury and repair processes. Many factors involved in neuroinflammation have been shown to regulate ARG, which highlights the pivotal role for ARG in such processes.

Selected inflammatory cytokines vary in their ability to stimulate ARG. Interleukin (IL)-13 and IL-4 induce ARG-1 overexpression via cAMP and the activation of JAK/STAT6 pathways $[95,96]$, while IL-13 induces expression of ARG-2 by its STAT3- but not its STAT6-mediated effect on IL-13Ra2 [97]. IL-10, on the other hand, stimulates ARG-1 minimally [98]. While the stimulatory effects of ILs have been well established, data on the effects of interferon (IFN)- $\gamma$ are inconclusive. Multiple studies have shown that IFN- $\gamma$ inhibits the activity of both ARGs [99], ARG-1 [98] and ARG-2 [100], although at least 1 report is contradictory [101]. Interestingly, in a murine model of autoimmune encephalitis, ARG inhibition with 2(S)-amino-6 -boronohexanoic acid (ABH) led to decreased production of IFN- $\gamma$ [102].

The regulation of ARG by cytokines appears to be a more complex process, where suppressors of cytokine signaling (SOCs) play a role via negative feedback inhibition on the JAK/STAT signaling pathway [103]. SOCs1 and SOCs3 are both expressed in microglia [103], and they regulate microglia activation [104] and macrophage polarization. Interestingly, this regulation is associated with changes in ARG/iNOS ratio; SOCs1 leads to a high 
ARG-to-iNOS ratio and M2 activation [105]. Knockdown of SOCs1, on the other hand, decreases M2-induced ARG-1 expression and activity, but also reciprocally enhances iNOS activity, SOCs3 expression associated with M1 activation [105], and the suppression of ARG-1 activity [106]. Considering that microglia are one of the first responders to injury in the neonatal brain and have been implicated in both beneficial and detrimental effects, these findings are critical to the understanding of postinjury processes.

Prostaglandin (PG)E1, PGE2, PGE3 [107], and transforming growth factor (TGF)- $\beta 1$ [108] have also been shown to modulate ARG expression.

\section{$A R G$ and Excitotoxicity}

ARG2 $2^{-/-}$knockout mice have been shown to have increased injury and neurologic impairment caused by MCAO and excitotoxic injury, likely due to L-arginine being redirected to the excitotoxicity-induced NOS pathway which leads to downstream oxidative stress [24]. Interestingly, however, it appears that polyamines, produced by the ARG metabolite ornithine, may exacerbate excitotoxicity by directly binding NMDA receptors [49]. Intraocular NMDA injections upregulate ARG-1, which presumably leads to increased ornithine and polyamine production, pharmacologic blockade of polyamine synthesis, and competitive blockade of polyamine binding sites on NMDA receptors, reducing excitotoxic retinal ganglion cell death [49].

A significant component of neuronal injury after neonatal brain HI results from excitotoxicity that stems from the pathologic release of excess glutamate. As studies have begun to elaborate the downstream signaling pathways that lead from glutamate receptor binding to cell death, most of the damage is thought to result from the oxidative stress induced by NOS upregulation and the increased production of NO. As NOS and ARG share the substrate L-arginine, many models seem to suggest that the shunting of L-arginine by the NOS pathway is neurotoxic, while alterations that would lead to increased ARG utilization of L-arginine might be neuroprotective. Competition between these 2 pathways may require a more delicate balance, however, as the polyamines that are produced downstream of ARG metabolites may themselves be neurotoxic [54]. Existing studies have just begun to aid our understanding of ARG metabolism in excitotoxic injury, but more study will be necessary to understand exactly how to harness these enzymatic pathways to maximize neuroprotection and minimize neuronal death.

\section{$A R G$ and Apoptosis}

It has been found that depletion of L-arginine by ARG results in neuronal starvation and impaired neuronal survival, inducing apoptosis and subsequent neuronal death [109]. In the same study, inhibition of ARG-1 with difluoromethylornithineO) reversed abnormal L-arginine utilization, suggesting a causal link between ARG activity and apoptotic death. In conflict with this report, however, overexpression of ARG-1 was found to prevent neuronal death, potentially via the suppression of NO production, and subsequent peroxynitrate production combined with an increase in polyamine synthesis [47]. ARG has also been shown to promote cell survival via the intracellular depletion of L-arginine, leading to the activation of the serine/threonine kinase, GCN2, to phosphorylate translational initiation factor $2 \alpha$ (IF-2 $\alpha$ ) associated with cell survival $[110,111]$.

\section{$A R G$ and Oxidative Stress}

The neonatal brain is selectively vulnerable to oxidative stress [112]. ARG and oxidative stress have a reciprocal relationship. ARG activity is stimulated by free radicals and activated ARG decreases the bioavailability of the NOS substrate, L-arginine, further increasing oxidative stress [113115]. Hydrogen peroxide $\left(\mathrm{H}_{2} \mathrm{O}_{2}\right)$ and peroxynitrite $\left(\mathrm{ONOO}^{-}\right)$lead to increased ARG activity and expression via protein kinase $\mathrm{C}$ activation and subsequent RhoA/Rhoassociated kinase activation [115], and this mechanism likely also occurs in microglial cells after injury [116].

In addition to this, ARG contributes to depletion of the substrate L-arginine for all 3 NOS isoforms, and NOS uncoupled from its substrate generates superoxide and/ or $\mathrm{H}_{2} \mathrm{O}_{2}$, a feature characteristic for all NOS isoforms [117]. The specific downstream effects of substrate depletion may vary depending on the NOS isoform; while eNOS uncoupling leads to radical formation resulting in endothelial damage, the deprivation of $\mathrm{L}$-arginine from iNOS is associated with a neuroprotective role of ARG, given the observed improvement in oxidative and nitrosative stress. The effects of substrate depletion may also differ with timing after injury. For example, during reperfusion, uncoupled iNOS is a source of free radicals and can contribute to significant reperfusion injury [117].

The contribution of L-arginine availability for NOS to radical formation is NOS isoform-dependent. While increased L-arginine availability for nNOS decreases the rate and amount of total radical production, in eNOS, it is only the rate that is affected [118]. Besides impaired NO formation, ARG also decreases the pro- 
duction of L-citrulline, which has been shown to have antioxidative properties [119], improve neuronal survival, and attenuate eNOS and nNOS expression after ischemic injury [120], restore NO levels, increase eNOS, and suppress iNOS after glutamate toxicity [121]. Treatment with L-arginine, on the other hand, increases iNOS [121]. All these findings indicate very fine-tuned roles for ARG in mediating oxidative stress and downstream injury mechanisms, thus highlighting the need for careful consideration of its effects, specifically on the NOS pathway.

\section{$A R G$ and the Regulation of the Blood-Brain Barrier}

The disruption of the blood-brain barrier (BBB), impaired cerebral autoregulation, and local changes in perfusion are the vascular pathophysiological features of $\mathrm{HI}$ and reperfusion injury of the brain. The role of ARG in vascular regulation and endothelial senescence has been extensively studied in several peripheral organs, and it is likely that at least some of these effects could be extrapolated to the brain. As ARG-1 and ARG-2 have both been detected in the cerebral microvasculature, it is assumed that ARG affects cerebral microcirculation, BBB integrity, and endothelial function (review [31]). The primary isoform in endothelial cells is ARG-2 [38], which, as discussed earlier, interacts with eNOS to regulate the production of NO [122]. Decreasing L-arginine availability for eNOS by ARG leads to eNOS uncoupling [123], which promotes oxidative stress. Upregulation of ARG leads to the induction of an endothelial senescence phenotype, eNOS-uncoupling, elevated adhesion molecule expression, and enhanced monocyte-endothelial cell interaction. While ARG-2 exhibits these effects through S6K1-signaling [30], ARG-1 does not [32]. Multiple vascular factors act as ARG inducers at the site of vascular injury. For example, the release of TGF- $\beta$ [124], or thrombin in endothelial cells which modulate endothelial ARG gene expression via the AP-1 promoter sequence-bound transcription factors c-Jun and ATF-2 [125]. Besides effects on local microcirculation, ARG stimulated by brain injury may also impact the systemic vasculature. ARG-1 expression increased in mesenteric arteries in a rat model of traumatic brain injury (TBI), and supplementation with L-arginine or ARG inhibition with nor-NOHA reversed the ARG effects [126]. However, the clinical significance of systemic changes in ARG expression after brain injury is unknown.

\section{Clinical Applications}

\section{$A R G$ as a Biomarker}

Both gene expression and serum activity of ARG-1 have been shown to increase in adult patients with acute ischemic stroke, and, more importantly, correlate with infarct volume and the severity of the stroke [127], suggesting a considerable role for ARG as a biomarker after stroke. Interestingly, ARG gene expression and serum protein levels also correlate with increases in peripheral neutrophil counts [127] which has been associated with poor neurological outcomes in asphyxiated newborns [128]. The relationship between ARG expression and neutrophils might be different in newborns, however, since neutrophils show different patterns of recruitment after stroke and migrate to the injury site at later time points than in to adults [129]. The utility of ARG as a biomarker is possible but needs to be examined further in validation cohorts.

\section{$A R G$ as a Therapy}

Given all the evidence thus far, the potential role of multiple steps of the ARG pathway in brain injury may represent a promising therapeutic target of neonatal brain HI. Manipulation of the ARG pathway at certain time points after the hypoxic insult may provide neuroprotection and potentially also enhance neurorestoration. To do this, however, besides establishing the appropriate time window for ARG inhibition, it is also important to characterize the effects of inhibition of the specific isoform of this enzyme. For example, in macrophage subpopulations, selective inhibition of ARG-1 in profibrotic M2 macrophages might lead to overexpression of the M1 inflammatory phenotype, which conversely predominantly expresses the ARG-2 isoform, and, in turn, aggravates iNOS-mediated inflammatory effects. On the other hand, inhibition of ARG-2 may enhance the profibrotic/repair M2 phenotype, with potential deleterious effects on vessels and other organs [130].

Different synthetic inhibitors of ARG have been produced, including boronic acid analogs, N-hydroxide-L-arginine, N-hydroxy-nor-L-arginine, and the newer (R)2-amino-6-borono-2-(2(piperidin-1yl)ethyl) hexanoic acid [130]. Currently, although there are approximately 27 ARG inhibitors patented and studied [131], studies have highlighted the lack of specificity in most of these inhibitors. While some insight into the effects of ARG inhibition might come from knockout models, the results need to be evaluated carefully, owing to unknown compensatory pathways that might mask the ARG effects. Of course, the lim- 
ited life-span of ARG-1 knockout also presents a considerable disadvantage. Despite this, however, ARG inhibitors have already been the subject of clinical trials showing promising effects in patients with cardiovascular disease (coronary artery disease, pulmonary hypertension, atherosclerosis, heart failure, vascular dysfunction in diabetes mellitus, and hypertension) [132-134].

The role of ARG inhibition after brain $\mathrm{HI}$ is unclear. While there are several studies describing the benefits of inhibiting ARG, some of these (discussed above) report the role of ARG as a neuroprotective enzyme. Comparing the effects of ARG inhibition is limited by the number of studies which are focused on different brain pathologies and the variety of time points for intervention.

The Benefits of ARG Activation

Increasing ARG activation/expression seems to be effective largely via the regulation of microglial polarization. Early treatment with miRNA-124, small noncoding RNA molecules involved in the posttranscriptional regulation of gene expression, has been shown to increase ARG-1 expression in immune cells, with polarization of macrophages/microglia towards the anti-inflammatory M2 phenotype associated with increased neuronal survival [71]. In mice subjected to TBI, administration of IL$2 \mathrm{C}$ increased the expression of arg1, among other genes, in the anti-inflammatory M2 microglia [135]. A similar effect has been observed in treatment with atorvastatin that increases M2 polarization and associated ARG-1 expression [136]. Considering that M2 microglia have been shown to elicit beneficial effects in the injured brain [137], these findings suggest modulating ARG expression after HI could have beneficial effects especially via microglial polarization. ARG catalytic function may be supported by manganese administration as shown in studies with a mouse model of Huntington disease, where manganese supplementation increased ARG-2 activity [138].

The Benefits of ARG Inhibition

In contrast, many studies have shown ARG inhibition following injury to be beneficial. In the brain, treatment with clomethiazole, associated with a decrease in ARG activity, was shown to be neuroprotective [139]. ARG inhibition has also been shown to decrease disease symptoms and accelerate recovery in a mouse model of autoimmune encephalitis [102], and to reduce injury volume in TBI [140] and MCAO [141], while ARG deletion significantly improves cerebral blood flow after TBI [142]. Caffeine is a commonly used medication with a high safety profile that decreases ARG activity; it acts via adenosine, a competitive
ARG inhibitor [143, 144]. As discussed earlier, it is likely that ARG has very specific effects based on age, timing, the organ affected, and isoform, and the conflicting nature of findings relating to ARG-mediated neuroprotection likely indicate the importance of careful extrapolation.

\section{Conclusion}

The ARG pathway is a complex metabolic pathway that is affected by multiple factors, and it appears that the ultimate effects do not occur in isolation, but rather as the culmination of complex interactions that can be species-, organ system-, and cell-specific. Currently, there are no specific inhibitors for the study of the effects on individual isoforms, and a knockout mouse shows a decreased life-span. Gender differences and gene polymorphisms may play a role. Despite these disadvantages, a better understanding of the effects of ARG on hypoxic-ischemic brain injury in newborns presents an attractive opportunity to develop new neuroprotective therapies.

\section{Acknowledgement}

We sincerely thank Donna Ferriero, Praneeti Pathipati, Sandrijn Vanschaik, and Jeff Fineman for their help and advice.

\section{Statement of Ethics}

The authors have no ethical conflicts to disclose.

\section{Disclosure Statement}

The authors have no conflicts of interest to declare.

\section{Funding Sources}

This study was funded by R35-5R35NS097299 (to D.F.) and the UCSF Pediatric Critical Care Division and Thrasher Research Fund P0530684.

\section{Author Contributions}

Jana Krystofova was the principal author, wrote the manuscript, checked references, and gave final approval. Jeffrey Russ, Praneeti Pathipati, and Ann Sheldon wrote the manuscript, checked references, and gave final approval. Donna Ferriero supplied supervision, wrote the manuscript, checked references, final approval. 


\section{References}

1 Lawn JE, Cousens S, Zupan J; Lancet Neonatal Survival Steering Team. 4 million neonatal deaths: when? Where? Why? Lancet. 2005 Mar;365(9462):891-900.

2 Millar LJ, Shi L, Hoerder-Suabedissen A, Molnár Z. Neonatal Hypoxia Ischaemia: Mechanisms, Models, and Therapeutic Challenges. Front Cell Neurosci. 2017 May;11:78.

3 Ferriero DM. Neonatal brain injury. N Engl J Med. 2004 Nov;351(19):1985-95.

4 Meijer AJ, Lamers WH, Chamuleau RA. Nitrogen metabolism and ornithine cycle function. Physiol Rev. 1990 Jul;70(3):701-48.

5 Caldwell RW, Rodriguez PC, Toque HA, Narayanan SP, Caldwell RB. Arginase: A Multifaceted Enzyme Important in Health and Disease. Physiol Rev. 2018 Apr;98(2):641-65.

6 Harpster MH, Bandyopadhyay S, Thomas DP, Ivanov PS, Keele JA, Pineguina N, et al. Earliest changes in the left ventricular transcriptome postmyocardial infarction. Mamm Genome. 2006 Jul;17(7):701-15.

7 Jeyabalan G, Klune JR, Nakao A, Martik N, Wu G, Tsung A, et al. Arginase blockade protects against hepatic damage in warm ischemia-reperfusion. Nitric Oxide. 2008 Aug; 19(1):29-35.

8 Shosha E, Xu Z, Yokota H, Saul A, Rojas M, Caldwell RW, et al. Arginase 2 promotes neurovascular degeneration during ischemia/reperfusion injury. Cell Death Dis. 2016 Nov; 7(11):e2483.

9 Ash DE. Structure and function of arginases. J Nutr. 2004 Oct;134(10 Suppl):2760S-4S.

10 Choi S, Park C, Ahn M, Lee JH, Shin T. Immunohistochemical study of arginase 1 and 2 in various tissues of rats. Acta Histochem. 2012 Sep;114(5):487-94.

11 Sparkes RS, Dizikes GJ, Klisak I, Grody WW Mohandas T, Heinzmann C, et al. The gene for human liver arginase (ARG1) is assigned to chromosome band 6q23. Am J Hum Genet. 1986 Aug;39(2):186-93.

12 Yu H, Iyer RK, Kern RM, Rodriguez WI, Grody WW, Cederbaum SD. Expression of arginase isozymes in mouse brain. J Neurosci Res. 2001 Nov;66(3):406-22.

13 Gotoh T, Araki M, Mori M. Chromosomal localization of the human arginase II gene and tissue distribution of its mRNA. Biochem Biophys Res Commun. 1997 Apr;233(2):48791.

14 Vockley JG, Jenkinson CP, Shukla H, Kern RM, Grody WW, Cederbaum SD. Cloning and characterization of the human type II arginase gene. Genomics. 1996 Dec;38(2):11823.

15 Morris SM, Kepka-Lenhart D, Chen LC. Differential regulation of arginases and inducible nitric oxide synthase in murine macrophage cells. Am J Physiol. 1998 Nov;275:E740-7.

16 Iyer RK, Yoo PK, Kern RM, Rozengurt N, Tsoa R, O'Brien WE, et al. Mouse model for human arginase deficiency. Mol Cell Biol. 2002 Jul;22:4491-8.
17 Schlune A, Vom Dahl S, Häussinger D, Ensenauer R, Mayatepek E. Hyperargininemia due to arginase I deficiency: the original patients and their natural history, and a review of the literature. Amino Acids. 2015 Sep; 47(9):1751-62.

18 Munder M. Arginase: an emerging key player in the mammalian immune system. Br J Pharmacol. 2009 Oct;158(3):638-51.

19 Lange PS, Langley B, Lu P, Ratan RR. Novel roles for arginase in cell survival, regeneration, and translation in the central nervous system. J Nutr. 2004 Oct;134(10 Suppl): 2812S-7S.

20 Maarsingh H, Pera T, Meurs H. Arginase and pulmonary diseases. Naunyn Schmiedebergs Arch Pharmacol. 2008 Aug;378(2):171-84.

21 Pernow J, Jung C. The Emerging Role of Arginase in Endothelial Dysfunction in Diabetes. Curr Vasc Pharmacol. 2016;14:155-62.

22 Korrer MJ, Zhang Y, Routes JM. Possible role of arginase-1 in concomitant tumor immunity. PLoS One. 2014 Mar;9(3):e91370.

23 Schlüter KD, Schulz R, Schreckenberg R. Arginase induction and activation during ischemia and reperfusion and functional consequences for the heart. Front Physiol. 2015 Mar;6:65.

24 Ahmad AS, Shah ZA, Doré S. Protective Role of Arginase II in Cerebral Ischemia and Excitotoxicity. J Neurol Neurosci. 2016;7:pii 88.

25 Clarkson AN, Liu H, Pearson L, Kapoor M, Harrison JC, Sammut IA, et al. Neuroprotective effects of spermine following hypoxicischemic-induced brain damage: a mechanistic study. FASEB J. 2004 Jul;18(10):1114-6.

26 Clarkson AN, Liu H, Rahman R, Jackson DM, Appleton I, Kerr DS. Clomethiazole: mechanisms underlying lasting neuroprotection after hypoxia-ischemia. FASEB J. 2005 Jun; 24(8): 1-24.

27 Bonestroo $\mathrm{HJ}$, Nijboer $\mathrm{CH}$, van Velthoven CT, Kavelaars A, Hack CE, van Bel F, et al. Cerebral and Hepatic Inflammatory Response after Neonatal Hypoxia-Ischemia in Newborn Rats. Dev Neurosci. 2013;35(2-3): 197-211.

28 Narayanan SP, Suwanpradid J, Saul A, Xu Z, Still A, Caldwell RW, et al. Arginase 2 deletion reduces neuro-glial injury and improves retinal function in a model of retinopathy of prematurity. PLoS One. 2011;6(7):e22460.

29 Yang Z, Ming XF. Functions of arginase isoforms in macrophage inflammatory responses: impact on cardiovascular diseases and metabolic disorders. Front Immunol. 2014 Oct;5:533.

30 Yepuri G, Velagapudi S, Xiong Y, Rajapakse AG, Montani JP, Ming XF, et al. Positive crosstalk between arginase-II and S6K1 in vascular endothelial inflammation and aging. Aging Cell. 2012 Dec;11(6):1005-16.

31 Lucas R, Fulton D, Caldwell RW, Romero MJ. Arginase in the vascular endothelium: friend or foe? Front Immunol. 2014 Nov;5:589.
32 Zhu C, Yu Y, Montani JP, Ming XF, Yang Z Arginase-I enhances vascular endothelial inflammation and senescence through eNOSuncoupling. BMC Res Notes. 2017 Feb;10(1): 82.

33 Koo BH, Yi BG, Jeong MS, Kwon SH, Hoe KL Kwon YG, et al. Arginase II inhibition prevents interleukin-8 production through regulation of p38 MAPK phosphorylation activated by loss of mitochondrial membrane potential in nLDL-stimulated hAoSMCs. Exp Mol Med. 2018 Feb;50(2):e438.

34 Ming XF, Barandier C, Viswambharan H, Kwak BR, Mach F, Mazzolai L, et al. Thrombin stimulates human endothelial arginase enzymatic activity via RhoA/ROCK pathway: implications for atherosclerotic endothelial dysfunction. Circulation. 2004 Dec;110(24): 3708-14.

35 Scalera F, Closs EI, Flick E, Martens-Lobenhoffer J, Boissel JP, Lendeckel U, et al. Paradoxical effect of L-arginine: acceleration of endothelial cell senescence. Biochem Biophys Res Commun. 2009 Sep;386(4):650-5.

36 Romero MJ, Platt DH, Tawfik HE, Labazi M, El-Remessy AB, Bartoli M, et al. Diabetes-induced coronary vascular dysfunction involves increased arginase activity. Circ Res. 2008 Jan; 102(1):95-102.

37 Kim JH, Bugaj LJ, Oh YJ, Bivalacqua TJ, Ryoo $\mathrm{S}$, Soucy $\mathrm{KG}$, et al. Arginase inhibition restores NOS coupling and reverses endothelial dysfunction and vascular stiffness in old rats. J Appl Physiol (1985). 2009 Oct;107(4):1249_ 57.

38 Lim HK, Lim HK, Ryoo S, Benjo A, Shuleri K, Miriel V, et al. Mitochondrial arginase II constrains endothelial NOS-3 activity. Am J Physiol Heart Circ Physiol. 2007 Dec; 293(6):H3317-24.

39 Huynh NN, Andrews KL, Head GA, Khong SML, Mayorov DN, Murphy AJ, et al. Arginase II knockout mouse displays a hypertensive phenotype despite a decreased vasoconstrictory profile. Hypertension. 2009;54:294301

40 Handley RR, Reid SJ, Brauning R, Maclean P, Mears ER, Fourie I, et al. Brain urea increase is an early Huntington's disease pathogenic event observed in a prodromal transgenic sheep model and HD cases. Proc Natl Acad Sci USA. 2017 Dec;114(52):E11293-302.

41 Xu J, Begley P, Church SJ, Patassini S, Hollywood KA, Jüllig M, et al. Graded perturbations of metabolism in multiple regions of human brain in Alzheimer's disease: snapshot of a pervasive metabolic disorder. Biochim Biophys Acta. 2016 Jun;1862:1084-92.

42 Que LG, George SE, Gotoh T, Mori M, Huang YC. Effects of arginase isoforms on NO Production by nNOS. Nitric Oxide. 2002 Feb; 6(1):1-8.

43 Bogdan C. Nitric oxide synthase in innate and adaptive immunity: an update. Trends Immunol. 2015 Mar;36(3):161-78. 
$44 \mathrm{Li} \mathrm{H}$, Meininger CJ, Hawker JR Jr, Haynes TE, Kepka-Lenhart D, Mistry SK, et al. Regulatory role of arginase I and II in nitric oxide, polyamine, and proline syntheses in endothelial cells. Am J Physiol Endocrinol Metab. 2001 Jan;280(1):E75-82.

45 Shank RP, Campbell GL. Ornithine as a precursor of glutamate and GABA: uptake and metabolism by neuronal and glial enriched cellular material. J Neurosci Res. 1983;9(1): 47-57.

46 Lee EK, Hu C, Bhargava R, Ponnusamy R, Park H, Novicoff S, et al. AAV-based gene therapy prevents neuropathology and results in normal cognitive development in the hyperargininemic mouse. Gene Ther. 2013 Aug; 20(8):785-96.

47 Cai D, Deng K, Mellado W, Lee J, Ratan RR, Filbin MT. Arginase I and polyamines act downstream from cyclic AMP in overcoming inhibition of axonal growth MAG and myelin in vitro. Neuron. 2002 Aug;35:711-9.

48 Malaterre J, Strambi C, Aouane A, Strambi A, Rougon G, Cayre M. A novel role for polyamines in adult neurogenesis in rodent brain. Eur J Neurosci. 2004 Jul;20(2):317-30.

49 Pernet V, Bourgeois P, Di Polo A. A role for polyamines in retinal ganglion cell excitotoxic death. J Neurochem. 2007 Nov;103(4): 1481-90.

50 Grillo MA, Fossa T, Dianzani U. Arginase, ornithine decarboxylase and S-adenosylmethionine decarboxylase in chicken brain and retina. Int J Biochem. 1983;15(8):1081-4.

51 Peters D, Berger J, Langnaese K, Derst C, Madai VI, Krauss M, et al. Arginase and Arginine Decarboxylase - Where Do the Putative Gate Keepers of Polyamine Synthesis Reside in Rat Brain? PLoS One. 2013 Jun;8(6):e66735.

52 Nakamura H, Saheki T, Nakagawa S. Differential cellular localization of enzymes of Larginine metabolism in the rat brain. Brain Res. 1990 Oct;530:108-12.

53 Braissant O, Gotoh T, Loup M, Mori M, Bachmann C. L-arginine uptake, the citrulline-NO cycle and arginase II in the rat brain: an in situ hybridization study. Brain Res Mol Brain Res. 1999 Jul;70:231-41.

54 Lee J, Ryu H, Ferrante RJ, Morris SM Jr, Ratan RR. Translational control of inducible nitric oxide synthase expression by arginine can explain the arginine paradox. Proc Natl Acad Sci USA. 2003 Apr;100(8):4843-8.

55 Vexler ZS, Yenari MA. Does inflammation after stroke affect the developing brain differently than adult brain? Dev Neurosci. 2009; 31(5):378-93.

56 Yu H, Iyer RK, Yoo PK, Kern RM, Grody WW, Cederbaum SD. Arginase expression in mouse embryonic development. Mech Dev. 2002 Jul;115(1-2):151-5.

57 Crain JM, Nikodemova M, Watters JJ. Microglia express distinct M1 and M2 phenotypic markers in the postnatal and adult central nervous system in male and female mice. J Neurosci Res. 2013 Sep;91(9):1143-51.
58 Konarska L, Tomaszewski L. Studies on L-Arginase in Developing Rat Small Instestine, Brain, and Kidney. I. Ontogenic Evolution of Arginase lsoenzymes. Biochem Med Metab Biol. 1986 Apr;35(2):156-69.

59 Liu P, Smith PF, Appleton I, Darlington CL, Bilkey DK. Regional variations and age-related changes in nitric oxide synthase and arginase in the sub-regions of the hippocampus. Neuroscience. 2003;119(3):679-87.

60 Liu P, Smith PF, Appleton I, Darlington CL, Bilkey DK. Nitric oxide synthase and arginase in the rat hippocampus and the entorhinal, perirhinal, postrhinal, and temporal cortices: regional variations and age-related changes. Hippocampus. 2003;13(7):859-67.

61 Liu P, Smith PF, Appleton I, Darlington CL, Bilkey DK. Age-related changes in nitric oxide synthase and arginase in the rat prefrontal cortex. Neurobiol Aging. 2004 Apr;25(4): $547-52$.

62 Liu P, Smith PF, Appleton I, Darlington CL, Bilkey DK. Potential involvement of NOS and arginase in age-related behavioural impairments. Exp Gerontol. 2004 Aug;39(8):120722.

63 Badaut J, Copin JC, Fukuda AM, Gasche Y, Schaller K, da Silva RF. Increase of arginase activity in old apolipoprotein-E deficient mice under Western diet associated with changes in neurovascular unit. J Neuroinflammation. 2012 Jun;9(1):132.

64 Shimizu H, Kakimoto Y, Sano I. Changes in concentration of polyamines in the developing mouse brain. Nature. 1965 Sep;207(5002): $1196-7$.

65 Murthy MR, Rappoport DA. Biochemistry of the developing rat brain VI. Preparation and properties of ribosomes. Biochim Biophys Acta. 1965 Jan;95(1):132-45.

66 Cantero G, Liu XB, Mervis RF, Lazaro MT, Cederbaum SD, Golshani P, et al. Rescue of the Functional Alterations of Motor Cortical Circuits in Arginase Deficiency by Neonatal Gene Therapy. J Neurosci. 2016 Jun;36(25): 6680-90.

67 Becker-Catania SG, Gregory TL, Yang Y, Gau CL, de Vellis J, Cederbaum SD, et al. Loss of arginase I results in increased proliferation of neural stem cells. J Neurosci Res. 2006 Sep; 84(4):735-46.

68 Arteaga O, Álvarez A, Revuelta M, Santaolalla F, Urtasun A, Hilario E. Role of Antioxidants in Neonatal Hypoxic-Ischemic Brain Injury: New Therapeutic Approaches. Int J Mol Sci. 2017 Jan;18(2):265.

69 Swamy M, Salleh MJ, Sirajudeen KN, Yusof WR, Chandran G. Nitric oxide (no), citrulline - no cycle enzymes, glutamine synthetase and oxidative stress in anoxia (hypobaric hypoxia) and reperfusion in rat brain. Int J Med Sci. 2010 May;7(3):147-54

70 Quirié A, Demougeot C, Bertrand N, Mossiat C, Garnier P, Marie C, et al. Effect of stroke on arginase expression and localization in the rat brain. Eur J Neurosci. 2013 Apr;37(7):1193202.
71 Hamzei Taj S, Kho W, Riou A, Wiedermann D, Hoehn M. MiRNA-124 induces neuroprotection and functional improvement after focal cerebral ischemia. Biomaterials. 2016 Jun; 91:151-65.

72 Bathina S, Das UN. Brain-derived neurotrophic factor and its clinical implications. Arch Med Sci. 2015 Dec;11(6):1164-78.

73 Prieto CP, Krause BJ, Quezada C, San Martin R, Sobrevia L, Casanello P. Hypoxia-reduced nitric oxide synthase activity is partially explained by higher arginase- 2 activity and cellular redistribution in human umbilical vein endothelium. Placenta. 2011 Dec;32(12):93240.

74 Cowburn AS, Crosby A, Macias D, Branco C, Colaço RD, Southwood M, et al. HIF2 $\alpha$ arginase axis is essential for the development of pulmonary hypertension. Proc Natl Acad Sci USA. 2016 Aug;113(31):8801-6.

75 Martín-Aragón Baudel MA, Rae MT, Darlison MG, Poole AV, Fraser JA. Preferential activation of HIF-2 $\alpha$ adaptive signalling in neuronal-like cells in response to acute hypoxia. PLoS One. 2017 Oct;12(10):e0185664.

76 Xue J, Nelin LD, Chen B. Hypoxia induces arginase II expression and increases viable human pulmonary artery smooth muscle cell numbers via AMPKal signaling. Am J Physiol Lung Cell Mol Physiol. 2017 Apr; 312(4):L568-78.

77 Jin Y, Jin Y, Chen B, Tipple TE, Nelin LD. Arginase II is a target of miR-17-5p and regulates miR-17-5p expression in human pulmonary artery smooth muscle cells. Am J Physiol Lung Cell Mol Physiol. 2014 Jul;307(2):L197204

78 Chen B, Xue J, Meng X, Slutzky JL, Calvert AE, Chicoine LG. Resveratrol prevents hypoxia-induced arginase II expression and proliferation of human pulmonary artery smooth muscle cells via Akt-dependent signaling. Am J Physiol Lung Cell Mol Physiol. 2014 Aug;307(4):L317-25.

79 Pandey D, Nomura Y, Rossberg MC, Hori D, Bhatta A, Keceli G, et al. Hypoxia Triggers SENP1 (Sentrin-Specific Protease 1) Modulation of KLF15 (Kruppel-Like Factor 15) and Transcriptional Regulation of Arg2 (Arginase 2) in Pulmonary Endothelium. Arterioscler Thromb Vasc Biol. 2018 Apr;38(4):913-26.

80 Toby IT, Chicoine LG, Cui H, Chen B, Nelin LD. Hypoxia-induced proliferation of human pulmonary microvascular endothelial cells depends on epidermal growth factor receptor tyrosine kinase activation. Am J Physiol Lung Cell Mol Physiol. 2010 Apr;298(4):L600-6.

81 White HA, Jin Y, Chicoine LG, Chen B, Liu Y, Nelin LD. Hypoxic proliferation requires EGFR-mediated ERK activation in human pulmonary microvascular endothelial cells. Am J Physiol Lung Cell Mol Physiol. 2017 May; 312(5):L649-56. 
82 Nelin LD, Chicoine LG, Reber KM, English BK, Young TL, Liu Y. Cytokine-induced endothelial arginase expression is dependent on epidermal growth factor receptor. Am J Respir Cell Mol Biol. 2005 Oct;33(4):394-401.

83 Louis CA, Reichner JS, Henry WL, Mastrofrancesco B, Gotoh T, Mori M, et al. Distinct arginase isoforms expressed in primary and transformed macrophages: regulation by oxygen tension. Am J Physiol. 1998 Mar; 274:R775-82.

84 Zimmermann M, Beer L, Ullrich R, Lukovic D, Simader E, Traxler D, et al. Analysis of region specific gene expression patterns in the heart and systemic responses after experimental myocardial ischemia. Oncotarget. 2017 May;8(37):60809-25.

85 Grönros J, Kiss A, Palmér M, Jung C, Berkowitz D, Pernow J. Arginase inhibition improves coronary microvascular function and reduces infarct size following ischaemia-reperfusion in a rat model. Acta Physiol (Oxf). 2013 Jun; 208(2):172-9.

86 Gonon AT, Jung C, Katz A, Westerblad H, Shemyakin A, Sjöquist PO, et al. Local arginase inhibition during early reperfusion mediates cardioprotection via increased nitric oxide production. PLoS One. 2012;7(7):e42038.

87 Hein TW, Zhang C, Wang W, Chang CI, Thengchaisri N, Kuo L. Ischemia-reperfusion selectively impairs nitric oxide-mediated dilation in coronary arterioles: counteracting role of arginase. FASEB J. 2003 Dec;17(15):232830.

88 Jung C, Gonon AT, Sjöquist PO, Lundberg JO, Pernow J. Arginase inhibition mediates cardioprotection during ischaemia-reperfusion. Cardiovasc Res. 2010 Jan;85(1):147-54.

89 Zhu M, Goetsch SC, Wang Z, Luo R, Hill JA, Schneider J, et al. FoxO4 promotes early inflammatory response upon myocardial infarction via endothelial Arg1. Circ Res. 2015 Nov;117(11):967-77.

90 Gao X, Xu X, Belmadani S, Park Y, Tang Z, Feldman AM, et al. TNF-alpha contributes to endothelial dysfunction by upregulating arginase in ischemia/reperfusion injury. Arterioscler Thromb Vasc Biol. 2007 Jun;27(6) 1269-75.

91 Filiz S, Enis U, Mustafa I, Aysegul C, Elvan B. Protective Effect of Mesna on Intestinal Ischemia-reperfusion Injury by Nitric Oxide and Arginase in an Experimental Rat Model. Int J Pharmacol. 2017 Oct;13(8):1038-46.

92 Jeyabalan G, Tsung A, Klune J, Billiar T, Geller D. Arginase blockade as a strategy to mitigate liver ischemia-reperfusion (I/R) injury. J Am Coll Surg. 2006 Sep;203(3):S89-90.

93 Greenhalgh AD, Passos Dos Santos R, Zarruk JG, Salmon CK, Kroner A, David S. Arginase-1 is expressed exclusively by infiltrating myeloid cells in CNS injury and disease. Brain Behav Immun. 2016 Aug;56:61-7.

94 Zarruk JG, Greenhalgh AD, David S. Microglia and macrophages differ in their inflammatory profile after permanent brain ischemia. Exp Neurol. 2018 Mar;301 Pt B:120-32.
95 Zimmermann N, King NE, Laporte J, Yang M, Mishra A, Pope SM, et al. Dissection of experimental asthma with DNA microarray analysis identifies arginase in asthma pathogenesis. J Clin Invest. 2003 Jun;111(12): 1863-74.

96 Wei LH, Jacobs AT, Morris SM Jr, Ignarro LJ. IL-4 and IL-13 upregulate arginase I expression by cAMP and JAK/STAT6 pathways in vascular smooth muscle cells. Am J Physiol Cell Physiol. 2000 Jul;279(1):C24856.

97 Cho WK, Lee CM, Kang MJ, Huang Y, Giordano FJ, Lee PJ, et al. IL-13 receptor a2arginase 2 pathway mediates IL-13-induced pulmonary hypertension. Am J Physiol Lung Cell Mol Physiol. 2013 Jan;304(2): L112-24.

98 Hesse M, Modolell M, La Flamme AC, Schito M, Fuentes JM, Cheever AW, et al. Differential regulation of nitric oxide synthase- 2 and arginase- 1 by type $1 /$ type 2 cytokines in vivo: granulomatous pathology is shaped by the pattern of L-arginine metabolism. J Immunol. 2001 Dec;167:6533-44.

99 Modolell M, Corraliza IM, Link F, Soler G, Eichmann K. Reciprocal regulation of the nitric oxide synthase/arginase balance in mouse bone marrow-derived macrophages by TH1 and TH2 cytokines. Eur J Immunol. 1995 Apr;25(4):1101-4.

100 Wang WW, Jenkinson CP, Griscavage JM, Kern RM, Arabolos NS, Byrns RE, et al. Coinduction of arginase and nitric oxide synthase in murine macrophages activated by lipopolysaccharide. Biochem Biophys Res Commun. 1995 May;210(3):1009-16.

101 Liscovsky MV, Ranocchia RP, Gorlino CV, Alignani DO, Morón G, Maletto BA, et al. Interferon-gamma priming is involved in the activation of arginase by oligodeoxinucleotides containing CpG motifs in murine macrophages. Immunology. 2009 Sep;128(1 Suppl):e159-69.

102 Xu L, Hilliard B, Carmody RJ, Tsabary G, Shin H, Christianson DW, et al. Arginase and autoimmune inflammation in the central nervous system. Immunology. 2003 Sep; 110:141-8.

103 Baker BJ, Akhtar LN, Benveniste EN. SOCS1 and SOCS3 in the control of CNS immunity. Trends Immunol. 2009 Aug;30(8):392-400.

104 Qin H, Yeh WI, De Sarno P, Holdbrooks AT, Liu Y, Muldowney MT, et al. Signal transducer and activator of transcription-3/suppressor of cytokine signaling-3 (STAT3/ SOCS3) axis in myeloid cells regulates neuroinflammation. Proc Natl Acad Sci USA. 2012 Mar;109(13):5004-9.

105 Whyte CS, Bishop ET, Rückerl D, GasparPereira S, Barker RN, Allen JE, et al. Suppressor of cytokine signaling (SOCS) 1 is a key determinant of differential macrophage activation and function. J Leukoc Biol. 2011 Nov;90(5):845-54.
106 Schmok E, Abad Dar M, Behrends J, Erdmann H, Rückerl D, Endermann T, et al. Suppressor of Cytokine Signaling 3 in Macrophages Prevents Exacerbated Interleukin-6-Dependent Arginase-1 Activity and Early Permissiveness to Experimental Tuberculosis. Front Immunol. 2017 Nov; 8: 1537.

107 Bansal V, Syres K, Harbrecht BG, Ochoa JB Effect of prostoglandins in arginase I expression. J Surg Res. 2003 Oct;114(2):288.

108 Zhou X, Spittau B, Krieglstein K. TGF $\beta$ signalling plays an important role in IL4-induced alternative activation of microglia. J Neuroinflammation. 2012 Sep;9(1):210.

109 Kan MJ, Lee JE, Wilson JG, Everhart AL, Brown CM, Hoofnagle AN, et al. Arginine deprivation and immune suppression in a mouse model of Alzheimer's disease. J Neurosci. 2015 Apr;35(15):5969-82.

110 Estévez AG, Sahawneh MA, Lange PS, Bae $\mathrm{N}$, Egea M, Ratan RR. Arginase 1 regulation of nitric oxide production is key to survival of trophic factor-deprived motor neurons. J Neurosci. 2006 Aug;26(33):8512-6.

111 Sattlegger E, Swanson MJ, Ashcraft EA, Jennings JL, Fekete RA, Link AJ, et al. YIH1 is an actin-binding protein that inhibits protein kinase GCN2 and impairs general amino acid control when overexpressed. J Biol Chem. 2004 Jul;279(29):29952-62.

112 Ferriero DM. Oxidant mechanisms in neonatal hypoxia-ischemia. Dev Neurosci. 2001;23(3):198-202.

113 Thengchaisri N, Hein TW, Wang W, Xu X, Li Z, Fossum TW, et al. Upregulation of arginase by $\mathrm{H} 2 \mathrm{O} 2$ impairs endothelium-dependent nitric oxide-mediated dilation of coronary arterioles. Arterioscler Thromb Vasc Biol. 2006 Sep;26(9):2035-42.

114 Sankaralingam S, Xu H, Davidge ST. Arginase contributes to endothelial cell oxidative stress in response to plasma from women with preeclampsia. Cardiovasc Res. 2010 Jan;85(1):194-203.

115 Chandra S, Romero MJ, Shatanawi A, Alkilany AM, Caldwell RB, Caldwell RW. Oxidative species increase arginase activity in endothelial cells through the RhoA/Rho kinase pathway. Br J Pharmacol. 2012 Jan; 165(2):506-19.

116 Pathipati P, Müller S, Jiang X, Ferriero D. Phenotype and secretory responses to oxidative stress in microglia. Dev Neurosci. 2013; 35(2-3):241-54.

117 Berka V, Liu W, Wu G, Tsai AL. Comparison of oxygen-induced radical intermediates in iNOS oxygenase domain with those from nNOS and eNOS. J Inorg Biochem. 2014 Oct;139:93-105.

118 Berka V, Wang LH, Tsai AL. Oxygen-induced radical intermediates in the nNOS oxygenase domain regulated by L-arginine, tetrahydrobiopterin, and thiol. Biochemistry. 2008 Jan;47(1):405-20. 
119 Marquet-de Rougé P, Clamagirand C, Facchinetti P, Rose C, Sargueil F, GuihenneucJouyaux C, et al. Citrulline diet supplementation improves specific age-related raft changes in wild-type rodent hippocampus. Age (Dordr). 2013 Oct;35(5):1589-606.

120 Yabuki Y, Shioda N, Yamamoto Y, Shigano M, Kumagai K, Morita M, et al. Oral L-citrulline administration improves memory deficits following transient brain ischemia through cerebrovascular protection. Brain Res. 2013 Jul;1520:157-67.

121 Lee KE, Kang YS. 1-Citrulline restores nitric oxide level and cellular uptake at the brain capillary endothelial cell line (TR-BBB cells) with glutamate cytotoxicity. Microvasc Res. 2018 Nov; 120:29-35.

122 Ryoo S, Lemmon CA, Soucy KG, Gupta G, White AR, Nyhan D, et al. Oxidized lowdensity lipoprotein-dependent endothelial arginase II activation contributes to impaired nitric oxide signaling. Circ Res. 2006 Oct;99(9):951-60.

123 Shin WS, Berkowitz DE, Ryoo SW. Increased arginase II activity contributes to endothelial dysfunction through endothelial nitric oxide synthase uncoupling in aged mice. Exp Mol Med. 2012 Oct;44(10):594602.

124 Jiang J, George SC. Enhanced Arginase Activity by TGF-beta 2 Impacts Nitric Oxide Production in Lung Epithelial Cells by Limiting L-Arginine Availability. B28. OXIDATIVE STRESS, SIGNAL TRANSDUCTION AND MECHANISMS OF LUNG INJURY/ Poster Discussion Session. Am J Respir Crit Care Med. 2010;181:A2699.

125 Zhu W, Chandrasekharan UM, Bandyopadhyay S, Morris SM Jr, DiCorleto PE, Kashyap VS. Thrombin induces endothelial arginase through AP-1 activation. Am J Physiol Cell Physiol. 2010 Apr;298(4):C952-60.

126 Villalba N, Sackheim AM, Nunez IA, HillEubanks DC, Nelson MT, Wellman GC, et al. Traumatic Brain Injury Causes Endothe- lial Dysfunction in the Systemic Microcirculation through Arginase-1-Dependent Uncoupling of Endothelial Nitric Oxide Synthase. J Neurotrauma. 2017 Jan;34(1): 192-203.

127 Petrone $\mathrm{AB}$, O'Connell GC, Regier MD, Chantler PD, Simpkins JW, Barr TL. The Role of Arginase 1 in Post-Stroke Immunosuppression and Ischemic Stroke Severity. Transl Stroke Res. 2016 Apr;7(2):103-10.

128 Morkos AA, Hopper AO, Deming DD, Yellon SM, Wycliffe N, Ashwal S, et al. Elevated total peripheral leukocyte count may identify risk for neurological disability in asphyxiated term neonates. J Perinatol. 2007 Jun; 27(6):365-70.

129 Povroznik JM, Engler-Chiurazzi EB, Nanavati T, Pergami P. Absolute lymphocyte and neutrophil counts in neonatal ischemic brain injury. SAGE Open Med. 2018. DOI: 2050312117752613

130 Steppan J, Nyhan D, Berkowitz DE. Development of novel arginase inhibitors for therapy of endothelial dysfunction. Front Immunol. 2013 Sep;4:278.

131 Ivanenkov YA, Chufarova NV. Small-molecule arginase inhibitors. Pharm Pat Anal. 2014 Jan;3(1):65-85.

$132 \mathrm{Wu} \mathrm{G}$, Morris SM. Arginine metabolism: nitric oxide and beyond. Biochem J. 1998 Nov; 336(Pt 1):1-17.

133 Zaiman A, Fijalkowska I, Hassoun PM, Tuder RM. One hundred years of research in the pathogenesis of pulmonary hypertension. Am J Respir Cell Mol Biol. 2005 Nov;33(5): 425-31.

134 Vadivel A, Aschner JL, Rey-Parra GJ, Magarik J, Zeng H, Summar M, et al. L-citrulline attenuates arrested alveolar growth and pulmonary hypertension in oxygen-induced lung injury in newborn rats. Pediatr Res. 2010 Dec;68(6):519-25.

135 Gao W, Li F, Zhou Z, Xu X, Wu Y, Zhou S, et al. IL-2/Anti-IL-2 Complex Attenuates Inflammation and BBB Disruption in Mice
Subjected to Traumatic Brain Injury. Front Neurol. 2017 Jun;8:281.

$136 \mathrm{Xu} \mathrm{X,} \mathrm{Gao} \mathrm{W,} \mathrm{Cheng} \mathrm{S,} \mathrm{Yin} \mathrm{D,} \mathrm{Li} \mathrm{F,} \mathrm{Wu} \mathrm{Y,}$ et al. Anti-inflammatory and immunomodulatory mechanisms of atorvastatin in a murine model of traumatic brain injury. J Neuroinflammation. 2017 Aug;14(1):167.

137 Ziemka-Nalecz M, Jaworska J, Zalewska T. Insights Into the Neuroinflammatory Responses After Neonatal Hypoxia-Ischemia. J Neuropathol Exp Neurol. 2017 Aug;76(8):644-54.

138 Bichell TJV, Wegrzynowicz M, Tipps KG, Bradley EM, Uhouse MA, Bryan M, et al. Reduced bioavailable manganese causes striatal urea cycle pathology in Huntington's disease mouse model. Biochim Biophys Acta. 2017 Jun;1863:1596-1604.

139 Clarkson AN, Liu H, Rahman R, Jackson DM, Appleton I, Kerr DS. Clomethiazole: mechanisms underlying lasting neuroprotection following hypoxia-ischemia. FASEB J. 2005 Jun;19(8):1036-8.

140 Cherian L, Sheiko T, Bryan R, Craigen W, Goodman CR. Inhibition of arginase with $\mathrm{N}$-hydroxy-nor-L-arginine (NOHA) reduces histological damage after cortical impact injury. J Neurotrauma. 2009;26:96.

141 Barakat W, Fahmy A, Askar M, El-Kannishy S. Effectiveness of arginase inhibitors against experimentally induced stroke. Naunyn Schmiedebergs Arch Pharmacol. 2018 Jun; 391(6):603-12.

142 Bitner BR, Brink DC, Mathew LC, Pautler RG, Robertson CS. Impact of arginase II on CBF in experimental cortical impact injury in mice using MRI. J Cereb Blood Flow Metab. 2010 Jun;30(6):1105-9.

143 Ofluoglu E, Pasaoglu H, Pasaoglu A. The effects of caffeine on $\mathrm{L}$-arginine metabolism in the brain of rats. Neurochem Res. 2009 Mar; 34(3):395-9.

144 Nikolic J, Bjelakovic G, Stojanovic I. Effect of caffeine on metabolism of L-arginine in the brain. Mol Cell Biochem. 2003 Feb;244: 125-8. 